\title{
Epidemiology of hodgkin's lymphoma
}

\author{
Zahra Mozaheb \\ Hematology-Oncology Department, Imam-Reza Hospital, Mashhad University of Medical Science, Mashhad, Iran; \\ mozahebz@muma.ac.ir
}

Received 3 March 2013; revised 4 April 2013; accepted 1 May 2013

Copyright (C) 2013 Zahra Mozaheb. This is an open access article distributed under the Creative Commons Attribution License, which permits unrestricted use, distribution, and reproduction in any medium, provided the original work is properly cited.

\begin{abstract}
The epidemiology of Hodgkin's Lymphoma (HL) varies with age at clinical onset. In developing countries, the disorder appears predominantly during childhood and its incidence decreases with age, while in industrialized countries, the incidence rate increase with age. There has long been a view that the differences in descriptive epidemiology of Hodgkin's Lymphoma around the world, and also between children, young adults and older adults may reflect differences in etiology between them. Hodgkin's Lymphoma has long been suspected to have an infectious precursor, and indirect evidence has implicated Epstein-Barr virus (EBV), as a causal agent. The etiology of EBV-negative cases remains obscure. Epidemiological investigation of the etiology of Hodgkin's Lymphoma is making steady progress, and it leads to a better understanding and hence prevention. This review considers in detail the descriptive and the etiological epidemiology of Hodgkin's Lymphoma.
\end{abstract}

Keywords: Hodgkin's

Lymphoma-Epidemiology-Etiology

\section{INTRODUCTION}

Hodgkin lymphoma (HL) is a malignant disease of the lymphoid tissue which originates from B lymphocyte and less common T lymphocyte. Hodgkin's Lymphoma characterized by the presence of multinucleated giant cell, and known as Red-Stenberg cell, in the background of numerous reactive lymphocyte [1,2]. There are marked geographic variations in Hodgkin's lymphoma incidence, but they are different for various age groups. There is also an interesting association between Hodgkin's lymphoma and markers of social class [3]. A higher incidence occurs in western countries and in westernized populations including those who emigrate from low in- cidence sites to the United States, but HL is less common in Asian countries, especially in the young adult [4]. Key issues which are highlighted in the descriptive and the etiological epidemiology of Hodgkin's Lymphoma include the evidence suggesting that HL is a complex of related conditions that are part mediated by infectious diseases, immune deficits and genetic susceptibilities. The apparent changing pattern of disease from country to country and by time needs careful future study [5]. Therefore; the comparison of HL rates in eastern and western countries could reveal the relative importance of environmental factors and genetic to disease etiology.

\section{DESCRIPTIVE EPIDEMIOLOGY}

Hodgkin's lymphoma is an uncommon disorder with heterogeneous clinical, histologic, and epidemiologic characteristics. Hodgkin's lymphoma is one of the most common malignancies at young adult ages, and is a curable disease in most patients [6]. The onset of HL in industrialized countries reveals a bimodal distribution with a first peak in the third decade and a second peak after the age of fifty and men are affected by HL slightly more often than women among all subtypes [7]. The annual age adjusted incidence rates of 2.4 and 2.8 per 100,000 in the UK and USA respectively [8]. Increasingly there is a great difference in incidence between western developed and developing countries, the disorder appears predominantly during childhood and its incidence decreases with age in developing countries [7]. The greatest recorded allage incidence rates of Hodgkin's Lymphoma are in whites in San Francisco and Connecticut, and in Italy. Rates are particularly low in India, Japan, China [9].

The most common subtype among the young adults, is nodular-sclerosis (NS). The frequency of mixed cellularity (MC) increases with age, while that of NS reaches a plateau in the group $>30$ years of age [7].

In one study in Iran we showed that HL was about 8\% of total lymphoid malignancies and the most common subtype was mixed cellularity (50\%) with mean age 
about 34 years, which was 10 years older than nodular sclerosing patients. In addition in our study like others our patients have a bimodal pattern of incidence, but it was less prominent than western countries Table 1 [2]. Totally Hodgkin's lymphoma has been reported to be rare in Asian countries.

One study in the US from 2000 to 2007, 16,710 cases of HL showed that Asians and black had low incidence (Asian/White IRR 0.43, P < 0.01; black/white incidence rate ratio (IRR) $0.86, \mathrm{P}<0.01$ ). The bimodal pattern of incidence also was less prominent for black males, Asian and black presented at a mean age of 38 years compared to 42 years for Whites $(\mathrm{P}<0.001)$ [10].

A point of considerable interest is that in the Danish data the 2 modes are of approximately equal prominence, whereas in the United States the $1^{\text {st }}$ mode is much less marked than the $2^{\text {nd }}$.

There are few studies in exploring the relative contributions of hereditary and environmental etiologic factors of Hodgkin's lymphoma, and individual risk factors in an Asians. A study which compared HL incidence rate in Chinese, Japanese, Filipino, and Asian Indian in the US and in Asia reports HL incidence rates were quite low in all Asian subgroups but approximately double in US Asian, as in native Asian. The consistently low rates of HL in native Asians suggest genetic resistance to the disease, possibly associated with HLA type. In addition, environmental and lifestyle difference between the Asia and USA is important. The other study from Eastern Asian countries and among Chinese immigrants in North America indicate increasing incidence trends for HL being associated with westernization [11]. A shift from Mixed Cellular dominant histologic subtype of HL seen over 20-year period within Japan, particularly in young adults [12].

Table 1. Frequency of Hodgkin's lymphoma sub-types in adults classified by WHO.

\begin{tabular}{|c|c|c|c|c|c|c|}
\hline Sub-type of HL & $\begin{array}{c}\mathrm{N} \\
\text { cases }\end{array}$ & $\begin{array}{c}\% \\
\text { of HL }\end{array}$ & $\begin{array}{l}\text { Median } \\
\text { age }\end{array}$ & $\mathrm{M} / \mathrm{F}$ & $\begin{array}{c}1^{\text {st }} \\
\text { mode }\end{array}$ & $\begin{array}{c}2^{\text {nd }} \\
\text { mode }\end{array}$ \\
\hline $\begin{array}{l}\text { Hodgkin } \\
\text { lymphoma }\end{array}$ & 41 & & 30.5 & 1.3 & $49 \%$ & $47 \%$ \\
\hline Classic HL & 39 & 95 & & & & \\
\hline $\begin{array}{l}\text { Nodular } \\
\text { sclerosis }\end{array}$ & 14 & $\begin{array}{c}36 \% \\
\mathrm{CH}\end{array}$ & 22 & & & \\
\hline $\begin{array}{c}\text { Mixed } \\
\text { cellularity }\end{array}$ & 20 & $\begin{array}{c}51 \% \\
\mathrm{CH}\end{array}$ & 33 & & & \\
\hline Lymphoctye-rich & 3 & $7 \% \mathrm{CH}$ & & & & \\
\hline $\begin{array}{l}\text { Lymphocyte- } \\
\text { depleted }\end{array}$ & 2 & $5 \% \mathrm{CH}$ & & & & \\
\hline $\begin{array}{c}\text { Nodular } \\
\text { lymphocytic } \\
\text { predominant HL }\end{array}$ & 2 & 5 & & & & \\
\hline
\end{tabular}

International and inter-ethnic differences and in casecontrol data risk factor patterns, implicate environmental influences in the etiology of HL [13]. Hodgkin's lymphoma tends to be more common in young adult with higher socio-economic classes [14]. In western countries, the young adult peak is largely consisted of nodular sclerosis tumors, whereas the rise at older ages are largely of mixed cellularity and lymphocytic-depleted histology [15], pattern of low social class determinants in children and older adult with HL, the age groups at risk for mixed cellularity (MC). These data support the involvement of the underling infectious agent given intense exposure, and EBV is a likely candidate based on its high prevalence in these groups [16]. Subtypes of HL in different countries are showed in below Table 2. The most common subtype of HL, based on different studies in the most Asian countries such as Iran, Korea, Thailand, Japan is mixed cellularity and relative paucity of NS subtype, particularly in males [13], which seems to be related to the etiologic factors of disease (environment and/ or inheritance).

\section{ETIOLOGIC EPIDEMIOLOGY}

Epidemiological data pointed towards an infectious agent as a potential cause of Hodgkin's Lymphoma. There is an association between early birth order, high maternal education, low number of siblings and playmates, single family dwellings in childhood and occurrence of HL in younger patients in developed countries [17]. An infectious agent is also in agreement with the clinical characteristics of HL, e.g. fever, weight loss, night sweat and the laboratory findings of elevated erythrocyte sedimenttation rate or interleukin 6 in the serum [18].

\subsection{EBV}

Recognition of an association of HL with infectious mononucleosis predates the discovery of EBV.

Table 2. Subtypes of Hodgkin's disease in various countries.

\begin{tabular}{cccccccc}
\hline HL & $\begin{array}{c}\text { Iran } \\
\mathrm{N}(\%)\end{array}$ & $\begin{array}{c}\text { Korea } \\
\mathrm{N}(\%)\end{array}$ & $\begin{array}{c}\text { Thailand } \\
\mathrm{N}(\%)\end{array}$ & Taiwan & $\begin{array}{c}\text { Japans } \\
\mathrm{N}(\%)\end{array}$ & $\begin{array}{c}\text { US } \\
\%\end{array}$ & $\begin{array}{c}\text { UK } \\
\%\end{array}$ \\
\hline NS & 14 & 26 & 58 & 29 & 70 & Up to & 60 \\
& $(34)$ & $(31.7)$ & $(36.9)$ & $(69)$ & $(42.4)$ & 80 & \\
MC & 20 & 38 & 64 & 2 & $51(31)$ & $<10$ & 15 \\
& $(48.7)$ & $(46.3)$ & $(40.8)$ & $(4.7)$ & & & \\
LD & 2 & $6(7.3)$ & 14 & 0 & $8(5)$ & 1 & rare \\
& $(4.8)$ & & $(8.9)$ & & & & \\
LP & 3 & $4(2.6)$ & 18 & $2(4.7)$ & $18(11)$ & 6 & 10 \\
& $(7.3)$ & & $(11.5)$ & & & & \\
NLPHD & 2 & $8(9.8)$ & $3(1.9)$ & $3(7.1)$ & $8(5)$ & 5 & 5 \\
Total & 41 & 82 & 157 & 36 & 155 & & \\
\hline
\end{tabular}


Several studies following up individuals who have had infectious mononucleosis have shown a raised risk of HL, generally with a relative risk of about 3 [19]. A study showed that persons with serologic evidence of EBV infection had 2.5- to 4-times the risk of developing HL as persons without EBV infection [20].

Remarkably, the change in lymphocyte cell population is sustained over years or longer [21]. The statistical analysis suggested that HL tended to occur 2.9 years after infectious mononucleosis [22,23].

Investigators have reported that EBV infectious mononucleosis is associated with a lifelong "immunologic scar" [23]. In recent studies, autoimmune and related conditions have drawn attention to a potential role for inflammatory and immune-related conditions in the pathogenesis and etiology of the malignancy [24]. Also there are new insights into infectious mononucleosis and disturbances in cellular immunity, new insight relating to the role that viruses may play in molecular pathogenesis of HL, an emerging appreciation of the increased incidence of HL in HIV and its relationship to immune suppression [21]. A role for suppression $\mathrm{T}$ cell suggested in the 1970s and increasing evidence shows a role for these cells in suppressing antitumor immune responses. EBV was more common in tumors in men than in women patients and was more prevalent with increasing age. In addition, the virus was more common in tumors of the mixed cellularity subtype than of the nodular sclerosis. The risk increase was essentially restricted to EBV-positive $\mathrm{HL}$ in younger adults, and conversely, no increased risk was seen for EBV-negative HL [25]. About 50\% of all cases of classical HL, in western countries are $E B V$ positive, means the virus is carried within the tumor cells. Detection of $E B V$ in tumors in these regions is least common in young adult disease especially those with the NS subtype. In some area such as Asia, Latin America, and Africa, the percentage is much higher with the percentage in children approaching 90\% - 100\% [26,27]. EBV genome has been found within the tumor in about $20 \%-40 \%$ of Hodgkin's lymphoma patients with a prior diagnosis of infectious mononucleosis [24]. The Mixed Cellular subtype harboring EBV DNA in up to $70 \%$ of cases and the Nodular Sclerosis subtype being positive in $15 \%-30 \%$ of cases [28]. Also in most Asian countries detection of $E B V$ in HL is less in young adults and are more detectable in older ages and children. Because of these differences, infectious cofactors other than $E B V$ have been suggested, but there is not a general agreement, in support of any other particular association [29].

As we mentioned $E B V$ induce immune suppression, and in an $E B V$ positive person, is more common (like $H I V$ positive) in MC subtype; therefore in MC subtype of $\mathrm{HL}$, which is more common in Asian countries, immunodeficiency has a more important role in comparison with other subtypes, Like Non-Hodgkin's Lymphoma which immune deficiency is one of the most important risk factors for them [30]. We can see the various subtypes of HL in different countries in Table 2.

Different studies show that the proportions of cases with EBV-positive tumors differed significantly across age, sex, ethnicity, histologic subtype, country of residence and regional economic level. Table 3 shows that in all age groups, MC and lymphocyte depleted were associated with high levels of EBV-positive cases, whereas NS and particularly Lymphocyte Predominant had relatively low percentages. In more developed regions, children with NS were at slightly higher risk of having EBV-positive disease than young adults, and found that the higher risks for females of EBV-positive NS in childhood and at older ages relative to young adulthood. Despite this variation, EBV prevalence was higher in children than in young adults for all subtypes. Across ethnic categories, the respective EBV prevalence in the 4 age groups (0 - 14, 15 - 39, 40 - 54, >55 years) was higher among Asians, Hispanics, and others than among, whites or blacks, who had relatively, low proportions at all ages [31].

Henrik Hjalgrim, et al. based on their study suggested that the risk of EBV-positive HL in young adulthood was inversely associated with the number of younger siblings, consistent with late primary EBV infection being causally involved in HL development [32].

Therefore the proportion of cases of HL that are associated with EBV is greater: 1) mixed cellularity and lymphocyte depleted than for nodular sclerosis and lymphocyte predominant subtypes; 2) in children (but not adults) from less economically developed than from more developed areas; 3) in males than in females (except at ages over 50); 4) in Asians and Hispanics than in blacks and whites; 5) in children and older adults than in young adults [19,33].

Some studies suggested that tumor EBV status may carry prognostic significance in both younger (favorable) and older (unfavorable) adult patients [34,35]. Finally, it is possible that tumor EBV status defines etiologically distinct diseases, means, EBV-positive and EBV negative Hodgkin's Lymphoma [36,37].

Table 3. Percentage of EBV-positive patients in each histologic subtype- and age-specific group.

\begin{tabular}{cccccc}
\hline HL subtype\% & Age (year) & $0-14$ & $15-39$ & $40-54$ & +55 \\
\hline$N S$ & 40 & 18 & 22 & 41 \\
$L P$ & 17 & 16 & 12 & 23 \\
$M S$ & 79 & 70 & 80 & 62 \\
$L D$ & 82 & 41 & 82 & 50 \\
\hline
\end{tabular}




\subsection{HIV}

An excess of Hodgkin's disease has been noted in people with HIV infection, especially those with AIDS, for whom a relative risk of about 10 has been found $[38,39]$, the risk is likely to relate to immunosuppression $[39,40]$.

Hodgkin's lymphoma in the setting of HIV has distinctive features and is usually associated with EBV infection [41]. HL in patients with $H I V$ tends to present at an advanced stage with associated B symptoms and extranodal involvement and is most often a mixed cellularity and lymphocyte-depleted subtypes [40]. Model fitting suggested that for persons with AIDS with moderate immunosuppretion at the onset of AIDS, HL risk was 15fold higher than in the general population. Lower CD4 counts were associated with less risk, the risk fall as CD4 count fall [21].

In a register of 500 tumours in people with congenital immunodeficiency, 9\% were Hodgkin's disease [42], and a significant relative risk of 6 has been found for Hodgkin's Lymphoma in patients who have undergone allogeneic bone marrow transplantation [43].

\section{INHERITANCE}

The risk of developing HL among family member of patients affected by HL increase from three-to nine-fold [45]. One study showed a significant association between HL and parental consanguinity and pointed to the possible etiologic role of recessive inheritance [45]. Evidence from multiple affected families from case series, a casecontrol study, a twin study, and population-based Registry studies implicate a role for genetic factors [24].

The relative risk for $\mathrm{HL}$ among first degree relatives of cases compared with controls was 3.1. Relative risks were higher in males compared with females, and in siblings of cases compared with parents and offspring. Identifying inherited susceptibility genes is an important step towards defining the pathway leading to development of HL and understanding its etiology. There are many studies of somatic mutations in HL tumor cells, but although there are associations with HLA types, specific germline genes causing susceptibility have not yet been identified. On the other hand it is not known whether or how extrinsic risk factors interact with genetic susceptibility [46]. Genetic susceptibility to HL has been shown by associations demonstrated to various HLA antigens [47].

Oza et al. in the single study of HL-HLA relationship found that HLA-DPB1*0301 increased risk of HL in all ethnic groups, while HLA-DPB $1 * 0401$ was associated with a lowered risk of HL in Japanese and Chinese and an elevated risk for US whites and Israelis [48]. Therefore; HLA-DPB1*1401, or factors related to it, could explain some of the lower incidence of HL in certain Asian ethnic groups, although environmental factors in- volves as well and indicate that HL etiology is complex.

A study that analyzed the Swedish Cancer Registry and compared with a matched healthy cohort revealed that HL was fourth in a list of cancers with high familial indices, just behind cancer affecting eye or testis (52 first degree relatives/8766 HL cases) [49]. But, familial Hodgkin’s Lymphoma is estimated to contribute to only a minority of cases. In addition, no consistent mechanisms of inheritance have been identified so far and evidence for a genetic aberration present in all cases of familial HL is lacking.

Young adults (ages 15 - 39) HL risk, was associated with having fewer siblings, living in the single vs. multiple house, and having better educated parents, whereas in older adults (ages 55 and older), and children (ages 0 14), risk increased with measures of more rather than fewer social exposure in childhood [19]. A study showed a protective role for increased early oral exposure to the microbiome, suggesting that factors associated with increased T helper Type 2 (Th2) and decreased T helper Type 1 (Th1) cytokines are etiologically relevant to young adult HL [50). Young adult HL is a heritable cancer, and susceptibility has been linked to genetically determine higher Interleukin 6 (a Th2 cytokine) and lower Interleukin 12 (a Th1 cytokine) responses. Together these data are quite consistent with the exposure model known as the "hygiene hypothesis" a etiologic model for adolescent/young adult Hodgkin lymphoma [51]. These results emphasize an interaction between genetic and environmental risk factors in Hodgkin's lymphoma [24].

\section{CONCLUSION}

There is evidence of etiologic heterogeneity among types of NHL, with different incidence patterns according to age, sex, race and specially geography. The extent to which these differences reflect differences in etiology needs further study.

Epidemiologic studies indicate that environmental factors may play an important role in the etiology of hodgkin's lymphoma, especially some infectious agents in the developing world, and they are significant causes of some subtype of HL. Future epidemiologic research on HL will be enhanced by the analyses of subtypes of HL, the improved reliability and validity of exposure assessment tools to evaluate environmental, and the evaluation of susceptible subgroups of individuals whose risk of HL may differ from that of the general population. Finding the relation between environmental factors and inheritance in etiology of HL is also important and it needs more investigation.

Lower rate of Hodgkin Lymphoma in Asian countries is suggestive of genetic resistance, in addition, international and inter-ethnic differences implicate environmental influence. Differences in HL risk reported in sev- 
eral studies indicate that such studies of HL risk factors should be conducted for specific Asian population.

\section{REFERENCES}

[1] Mirsadraee, S., Farzadnia, M., Heidary, F., Rahimi, M., Jabbari Noghabi, H. and Kakhki, S. (2011) A comparative immumohistochemical diagnosis of Hodgkin's Lymphoma with conventional method.

[2] Classical, H., Michael, C., Jame, A., Wyndham, H.W. and Elaine, S.J. (2009) Bethesda handbook of clinical hematology, Lippincott Williams \& Wilkins, Philadelphia.

[3] Mozaheb, Z. (2012) Epidemiology of lymphoid malignnancy in Asia epidemiology insights. Mashhad University of Medical Science, Mashhad.

[4] Mozaheb, Z., Aledavood, A. and Farzad, F. (2011) Distributions of major sub-types of lymphoid malignancies among adults in Mashhad, Iran. Cancer Epidemiology, 35, 26-29. doi:10.1016/j.canep.2010.09.009.

[5] Cartwright, R.A. and Watkins, G. (2004) Epidemiology Of hodgkin's disease: A review. Hematological Oncology, 22, 11-26. doi:10.1002/hon.723

[6] Flowers, C.R. and Armitage, J.O. (2010) A Decade of progress in lymphoma: advances and continuing challenges. Clinical Lymphoma Myeloma and Leukemia, 10, 414-423. doi:10.3816/CLML.2010.n.086.

[7] Thomas, R., Re, D., Zander, T., Wolf, J. and Diehl, V. (2002) Epidemiology and etiology of Hodgkin's lymphoma. Annals of oncology, 13, 147-152. doi:10.1093/annonc/mdf652.

[8] Ries, L.A.G., Miler, B.A., Hankey, B.F. and Harras, A.E.B.K. (1994) SEER cancer statistics review, 1973-1991: Tables and graphs. National Institutes of Health, National Cancer Institute, Bethesda.

[9] Swerdlow, A.J. (2003) Epidemiology of hodgkin's disease and non-Hodgkin's lymphoma. European Journal of $\mathrm{Nu}$ clear Medicine and Molecular Imaging, 30, S3-S12. doi:10.1007/s00259-003-1154-9

[10] Pareen, S., Alison, M., Neha, M. and Christopher, R. (2011) Incidence patterns and outcomes for hodgkin lymphoma patients in the United States. Advances in Hematology, 2011, 725219.

[11] Caporaso, N.E., Goldin, L.R., Anderson, W.F. and Landgren, O. (2009) Current insight on trends, causes, and mechanisms of Hodgkin's lymphoma. The Cancer Journal, 15, 117-123. doi:10.1097/PPO.0b013e3181a39585.

[12] Aozasa, K., Ueda, T., Tamai, M. and Tsujimura T. (1986) Hodgkin's disease in Osaka, Japan (1964-1985). European Journal of Cancer and Clinical Oncology, 22, 11171119. doi:10.1016/0277-5379(86)90016-7

[13] Glaser, S.L. and Hsu, J.L. (2002) Hodgkin's disease in Asians: Incidence patterns and risk factors in populationbased data. Leukemia Research, 26, 261-269. doi:10.1016/S0145-2126(01)00126-6.

[14] Correa, P. and O’Conor, G.T. (1971) Epidemiologic patterns of Hodgkin's disease. International Journal of Cancer, 8, 192-201. doi:10.1002/ijc.2910080203.
[15] Spitz, M., Sider, J., Johnson, C., Butler, J., Pollack, E. and Newell, G. (1986) Ethnic patterns of Hodgkin's disease incidence among children and adolescents in the United States, 1973-1982. Journal of the National Cancer Institute, 76, 235-239.

[16] Glaser, S.L. and Jarrett, R.F. (1996) The epidemiology of Hodgkin's disease. Baillière's Clinical Haematology, 9, 401-416. doi:10.1016/S0950-3536(96)80018-7

[17] Thomas, R.K., Re, D., Zander, T., Wolf, J. and Diehl, V. (2002) Epidemiology and etiology of Hodgkin's lymphoma. Annals of Oncology, 13, 147-152. doi:10.1093/annonc/mdf652

[18] Wolf, J. and Diehl, V. (1994) Is Hodgkin's disease an infectious disease? Annals of Oncology, 5, S105-S111. doi:10.1093/annonc/5.suppl_1.S105.

[19] Swerdlow, A.J. (2003) Epidemiology of Hodgkin's disease and non-Hodgkin's lymphoma. European Journal of Nuclear Medicine and Molecular Imaging, 30, S3-S12. doi:10.1007/s00259-003-1154-9.

[20] Mueller, N., Evans, A., Harris, N.L., Comstock, G.W., Jellum, E., Magnus, K., et al., (1989) Hodgkin's disease and Epstein-Barr virus. New England Journal of Medicine, 320, 689-695. doi:10.1056/NEJM198903163201103.

[21] Ambinder, R.F. (2007) Epstein-Barr virus and Hodgkin Lymphoma. Hematology, 2007, 204-209. doi:10.1182/asheducation-2007.1.204

[22] Hjalgrim, H., Askling J., Rostgaard, K., Hamilton-Dutoit, S., Frisch, M., Zhang, J.-S., et al., (2003) Characteristics of Hodgkin's Lymphoma after infectious mononucleosis. New England Journal of Medicine, 349, 1324-1332. doi:10.1056/NEJMoa023141.

[23] Sauce, D., Larsen, M., Leese, A., Millar, D., Khan, N., Hislop, A., et al., (2007) IL 7R versus CCR7 and CD45 as markers of virus specific CD8+ $\mathrm{T}$ cell differentiation: Contrasting pictures in blood and tonsillar lymphoid tissue. Journal of Infectious Diseases, 195, 268-278. doi:10.1086/510248.

[24] Landgren, O. and Caporaso, N.E. (2007) New aspects in descriptive, etiologic, and molecular epidemiology of Hodgkin's Lymphoma. Hematology/Oncology Clinics of North America, 21, 825-840. doi:10.1016/j.hoc.2007.07.001.

[25] Hjalgrim, H., Ekström Smedby, K., Rostgaard, K., Molin, D., Hamilton-Dutoit, S., Chang, E.T., et al., (2007) Infectious mononucleosis, childhood social environment, and risk of Hodgkin lymphoma. Cancer research, 67, 2382. doi:10.1158/0008-5472.CAN-06-3566.

[26] Glaser, S.L., Lin, R.J., Stewart, S.L., Ambinder, R.F., Jarrett, R.F., Brousset, P., et al., (1997) Epstein Barr virus associated Hodgkin's disease: Epidemiologic characteristics in international data. International Journal of Cancer, 70, 375-382.

doi:10.1002/(SICI)1097-0215(19970207)70:4<375::AIDIJC1>3.0.CO;2-T.

[27] Zarate-Osorno, A., Roman, L.N., Kingma, D.W., Meneses-Garcia, A. and Jaffe, E.S. (1995) Hodgkin's disease in Mexico. Prevalence of Epstein Barr virus sequences and correlations with histologic subtype. Cancer, 75, 1360- 
1366.

doi:10.1002/1097-0142(19950315)75:6<1360::AID-CNC $\underline{\text { R2820750619>3.0.CO;2-U. }}$

[28] Brousset, P., Chittal, S., Schlaifer, D., Icart, J., Payen, C., Rigal-Huguet, F., et al., (1991) Detection of Epstein-Barr virus messenger RNA in Reed-Sternberg cells of Hodgkin's disease by in situ hybridization with biotinylated probes on specially processed modified acetone methyl benzoate xylene (ModAMeX) sections [see comments]. Blood, 77, 1781.

[29] Wilson, K., Freeland, J., Gallagher, A., Cosby, S., Earle, J., Alexander, F., et al. (2007) Measles virus and classical Hodgkin lymphoma: No evidence for a direct association. International Journal of Cancer, 121, 442-447. doi:10.1002/ijc.22629.

[30] Mozaheb, Z., Aledavood, A. and Farzad, F. (2012) Diet and non-Hodgkin's lymphoma risk. The Pan African Medical Journal, 12.

[31] Glaser, S.L., Lin, R.J., Stewart, S.L., Ambinder, R.F., Jarrett, R.F., Brousset, P., et al. (1997) Epstein-Barr virusassociated Hodgkin's disease: Epidemiologic characteristics in international data. International Journal of Cancer, 70, 375-382.

doi:10.1002/(SICI)1097-0215(19970207)70:4<375::AIDIJC1>3.0.CO;2-T.

[32] Hjalgrim, H., Ekström Smedby, K., Rostgaard, K., Molin, D., Hamilton-Dutoit, S., Chang, E.T., et al. (2007) Infectious mononucleosis, childhood social environment, and risk of Hodgkin lymphoma. Cancer Research, 67, 23822328. doi:10.1158/0008-5472.CAN-06-3566.

[33] Flavell, K.J., Biddulph, J.P., Powell, J.E., Parkes, S.E., Redfern, D., Weinreb, M., et al. (2001) South Asian ethnicity and material deprivation increase the risk of Epstein-Barr virus infection in childhood Hodgkin's disease. British Journal of Cancer, 85, 350-356. doi:10.1054/bjoc.2001.1872

[34] Keegan, T.H.M., Glaser, S.L., Clarke, C.A., Gulley, M.L., Craig, F.E., DiGiuseppe, J.A., et al. (2005) Epstein-Barr virus as a marker of survival after Hodgkin's lymphoma: A population-based study. Journal of Clinical Oncology, 23, 7604-7613. doi:10.1200/JCO.2005.02.6310.

[35] Jarrett, R.F., Stark, G.L., White, J., Angus, B., Alexander, F.E., Krajewski, A.S., et al. (2005) Impact of tumor Epstein-Barr virus status on presenting features and outcome in age-defined subgroups of patients with classic Hodgkin lymphoma: a population-based study. Blood, 106, 24442451. doi:10.1182/blood-2004-09-3759

[36] Jarrett, R.F. (2002) Viruses and Hodgkin's lymphoma. Annals of Oncology, 13, 23-29.

[37] Armstrong, A.A., Alexander, F.E., Cartwright, R., Angus, B., Krajewski, A.S., Wright, D.H., et al. (1998) EpsteinBarr virus and Hodgkin's disease: Further evidence for the three disease hypothesis. Leukemia, 12, 1272-1276. doi:10.1038/sj.leu.2401097

[38] Goedert, J.J., (2000) The epidemiology of acquired immunodeficiency syndrome malignancies. Seminars in Oncology, 27, 390-401.

[39] Frisch, M., Biggar, R.J., Engels, E.A. and Goedert, J.J.
(2001) Association of cancer with AIDS-related immunosuppression in adults. The Journal of the American Medical Association, 285, 1736-1745. doi:10.1001/jama.285.13.1736

[40] Clarke, C.A. and Glaser, S.L. (2001) Epidemiologic trends in HIV-associated lymphomas. Current Opinion in Oncology, 13, 315-413. doi:10.1097/00001622-200109000-00007

[41] Glaser, S.L., Clarke, C.A., Gulley, M.L., Craig, F.E., DiGiuseppe, J.A., Dorfman, R.F., et al. (2003) Population based patterns of human immunodeficiency virus related Hodgkin lymphoma in the Greater San Francisco Bay Area, 1988-1998. Cancer, 98, 300-309. doi:10.1002/cncr.11459

[42] Filipovich, A., Mathur, A., Kamat, D. and Shapiro, R. (1992) Primary immunodeficiencies: Genetic risk factors for lymphoma. Cancer Research, 52, 5465S.

[43] Rowlings, P.A., Curtis, R.E., Passweg, J.R., Deeg, H.J., Socié, G., Travis, L.B., et al. (1999) Increased incidence of Hodgkin's disease after allogeneic bone marrow transplantation. Journal of Clinical Oncology, 17, 3122-3127.

[44] Haim, N., Cohen, Y. and Robinson, E. (1982) Malignant lymphoma in first degree blood relatives. Cancer, 49, 2197-2200. doi:10.1002/1097-0142(19820515)49:10<2197::AID-CN CR2820491036>3.0.CO;2-9.

[45] Abramson, J., Pridan, H., Sacks, M., Avitzour, M., Peritz, E. (1978) A case-control study of Hodgkin's disease in Israel. Journal of the National Cancer Institute, 61, 307-314.

[46] Goldin, L., McMaster, M., Ter-Minassian, M., Saddlemire, S., Harmsen, B., Lalonde, G., et al. (2005) A genome screen of families at high risk for Hodgkin lymphoma: Evidence for a susceptibility gene on chromosome 4 . Journal of Medical Genetics, 42, 595-601. doi:10.1136/jmg.2004.027433.

[47] Easton, D. and Peto, J. (1990) The contribution of inherited predisposition to cancer incidence. Cancer Survivors, 9, 395-416.

[48] Oza, A.M., Tonks, S., Lim, J., Fleetwood, M.A., Lister, T.A., Bodmer, J.G., et al. (1994) A clinical and epidemicological study of human leukocyte antigen-DPB alleles in Hodgkin's disease. Cancer Research, 54, 5101.

[49] Lindelöf, B. and Eklund, G. (2001) Analysis of hereditary component of cancer by use of a familial index by site. The Lancet, 358, 1696-1698. doi:10.1016/S0140-6736(01)06721-6

[50] Matricardi, P.M. and Bonini, S. (2000) High microbial turnover rate preventing atopy: A solution to inconsistencies impinging on the Hygiene hypothesis? Clinical \& Experimental Allergy, 30, 1506-1510. doi:10.1046/j.1365-2222.2000.00994.x.

[51] Cozen, W., Hamilton, A.S., Zhao, P., Salam, M.T., Deapen, D.M., Nathwan, B.N., et al. (2009) A protective role for early oral exposures in the etiology of young adult Hodgkin lymphoma. Blood, 114, 4014-4020. doi:10.1182/blood-2009-03-209601. 